\title{
Problem of translation of certain implicit grammatical categories
}

\author{
Irina V. Timoshenko
}

DOI: 10.18355/XL.2019.12.02.13

\begin{abstract}
The paper presents the results of contrastive analysis of linguistic units used to indicate the reference type of nouns and nominal groups in articled and articleless languages based on translations of chapters of the novel "Master and Margarita" by M.A. Bulgakov from Russian into English and French. By isolating the article semantic invariant, which is common for the compared languages, and matching it with lexical, grammatical and syntactical means of the articleless language, the ways of implicit indication of different reference types have been identified. This paper gives an analysis of the transfer of the meaning of the original implicit language category by means of the overt category of the language into which the translation is done on the material of parallel texts performed by native speakers of the target language. Comparison of the use of articles in order to convey the identical meaning of the reference of nouns and nominal groups in translations made it possible to identify mismatches and consider the possible causes of these mismatches localized in the original language, as well as to study the fundamental admissibility of such discrepancies by the grammar of the languages into which the translation is done.
\end{abstract}

Key words: reference of a noun, implicit categories, article invariant, implicitness, non-sister languages, translation practice

\section{Introduction}

The specificity of translation as a process and a result determines the possibility of considering the activity of a translator as participation in written discourse, where a translator is simultaneously the addressee of the source text and the addresser of the translation text. However, he/she does not have the opportunity to get feedback from the author of the translated literary work. In conditions of such autonomous work, the information expressed implicitly in the translated text is interpreted by a translator independently. Theoretical and conceptual framework of literal translation by illuminating the studies of a number of researchers with different attitudes to this phenomenon. In the process of this interpretation, a translator creates his/her understanding not only of the text as a whole, but also of certain implicit language categories related to objects of extralinguistic reality. During the comparison of the elements of written discourse with certain components of the human realm, a translator actually determines the reference type of nouns and nominal groups included in the translated text. In this paper, the reference is understood as the correlation of the means of the language with the objects nominated by these means. In this case, the denotate lies outside the text and can refer to both human realm and virtual universes and worlds of literary works. I.S. Barkhudarov defines the reference in a similar way, saying that "objects, processes, qualities, phenomena of current reality, denoted by signs, are usually called referents of signs, and the relation between a sign and its referent - the referential meaning of the sign" (Barkhudarov, 1975: 66).

The consideration of implicit categories in the language and the peculiarities of their translation primarily require defining what is implicitness and the classifications of constituent elements of this phenomenon. K.A. Dolinin calls implicit such content "that is not directly embodied in the usual lexical and grammatical meanings of linguistic units making up the utterance, but is extracted or can be extracted from the latter when it is perceived" (Dolinin, 1983: 37). I.V. Arnold proposes to consider all 
implicit phenomena in the language as divided into 2 types: situational contentsubtext and associative content-subtext ones (Arnold, 1982: 121).

There are earlier studies that consider the issue of referential choice, but their focus is either on people spontaneously speaking their mother tongue (Litvin, 2014) or on people speaking the second language (the first foreign language) (Barton et al., 2015). The issues of translation into the mother tongue and the referential choice in the translation process have not been considered in these studies.

When translating from the articleless language into the language with articles, a translator acts as an "active listener", i.e. a recipient of written discourse, who uses his/her own language to determine referential connections of nouns and nominal groups. At the same time, he/she also plays the role of a "speaker" generating a text in the articled language. Therefore, in the absence of unambiguous indications of the reference type, a translator is guided by his/her understanding of the original text fragment, which can lead to discrepancies in the use of articles in different translations of the same source text. F.A. Litvin notes that "reference is carried out in a communicative act by the addresser of the message", and "the situation named by the utterance is interpreted by that addresser" (Litvin, 2014: 89-99). Thus, a professional translator, who is a native speaker of the target language, perceives the original text fragment in the language, in which referential relations do not have any special means of expression, i.e. they fall under an implicit language category. In the process of translation, a translator transfers the indication of the reference type from the implicit language category to the explicit one, since in the translation language there are a special means of expressing the referential meaning of nouns and nominal groups. Such means is an article, the main purpose of which in this study is to indicate a reference type of nouns and nominal groups. The choice of a specific article form when translating is one of the specific manifestations of personal discourse which is considered by E. Benveniste as "the functioning of the language in living communication" (Benveniste, 1974). This researcher notes that a discursive act is a separate communicative event occurring in a specific communicative context, and an utterance is actually "speech given by the speaker" (Benveniste, 1974: 296).

Obviously, the use of the article for expressing the original referential meaning is not the result of some random choice, and despite the fact that articles in different languages have their own characteristics and properties, it is possible to distinguish a universal semantic invariant and provide the contrastive description of the article forms, including those in unrelated languages. This is most evident when comparing parallel texts of translations from the third language. One source text allows considering the indication of the same reference relations by different articles in situations which allow the translator to interpret the original text fragment in an ambiguous way. In addition, when studying parallel texts, one can trace the implementation of the universal article invariant in the languages being matched. At the same time, when studying the original text, one can consider the ways of indicating the reference type in a language that does not have a special part of speech for this, while preserving the need for the designation of the nature of referential links of nouns.

\section{Methods and Materials}

In order to study certain aspects of the problem of translating implicit language categories when working with a literary text, it is possible to examine the peculiarities of the transfer of a certain language category, the indication of which is implicit in the source language and overt in the target language. This is the reason for choosing the articles and features of their functioning to denote the reference type of a noun as an object of this research.

XLinguae, Volume 12, Issue 2, April 2019, ISSN 1337-8384, eISSN 2453-711X 
Parallel translations from Russian into English and French of chapters I and XXV of the novel "Master and Margarita" by M.A. Bulgakov (two translations for each of the languages) (Bulgakov, 1997, 2001, 2004, 2008, 2012) were selected as research material. This choice is not arbitrary and conditioned, first, by the possibility of both intralinguistic and interlinguistic analysis of the use of articles to determine the same implicit indication of the reference type of a noun in the original text in articleless Russian. This multicomponent analysis allows identifying the features of transfer of the referential meaning by means of implicit language categories, establishing specific language means used to convey a referential component of the meaning of nouns and nominal groups in articleless languages, as well as correlating these means with those previously identified in the author's scientific work (Timoshenko, 2017).

For studying the articles' functioning in the text, the description of the article system proposed by F.A. Litvin was used. Within the framework of this description, an invariant of the definite article is represented as the "selection from the class", an invariant of the indefinite article - as the "reference to the class", an invariant of the zero-article - as "nominating the class" (Litvin, 2014: 89-99). It means that the indefinite article is regarded as "classifying", the definite article - as "individualizing" and the zero article is used when "the quantitative principle is not applicable" (Litvin, 2014: 8).

When considering the texts of translations and correlating them with the source text, it is necessary to take into account the fundamental translatability of the original text fragment. The presence of untranslatable components (semantic and linguistic units) can force a translator to use translation transformations, comments (necessary for the reader's understanding of additional explanations absent in the original text) or, vice versa, reductions (omissions that are not critical for conveying the meaning of the original text fragment of untranslatable linguocultural and other structural units). Translatability/untranslatability regarding nouns of articleless languages is not reduced to the finding of regular formal equivalents only, but also involves the adequate transfer of the referential relations laid in the original text fragment.

When a translator is free to determine the reference type of a noun in the original text, he/she is not under additional pressure from the source language, as it happens in case of translating from articled languages, and on the part of the author, who can theoretically influence the translator's general perception of objects of reality of his literary work. In this case, a translator is in the situation that E. Benveniste defined as a phenomenon of "man in language". Within this phenomenon, a speaker, the role played by the translator in the situation under study, uses a special sign system - the language - to indicate the reference points determined by the speaker (Benveniste, 1974). A reference point is the primary introduction of an object into a discourse by means of the direct nomination of this object. It should be noted that not an objectively existing object of reality is actually introduced, but some mental image formed by the speaker during the perception of this object. In this case, the speaker perceives this image as a full-fledged reflection of the named object and as one of the elements of compound reality, establishing referential links with other elements. These links are identified at the reference points that the speaker chooses to indicate the relationship between the named object and the set, to which it is a part, and the context of the situation. In this case, a recipient of the statement may not have sufficient information about the object to which the reference is made, which can be either neglected by the speaker when indicating the type of referential links or taken into account.

Speaking of translation practice, the source text, not the human realm, plays the role of perceived reality for a translator. Thus, the reference points in the translation text are defined for the objects of the reality of the source text. Working with the original text fragment, a translator forms in his/her mind the image of the object named by the author and further actually transfers the meaning of his/her own mental 
formation determined by E.S. Kubryakova as "figurative representation", not a nounreferent contained in the source text (Kubryakova, 1997: 65). In oral discourse, figurative representation is refined and detailed by the speaker in his/her statement until the communicative goal, which usually consists in the inference, is reached. In written discourse, the author proceeds from his/her own understanding of how much information the reader needs to identify an object of extralinguistic reality, referenced by a noun or a nominal group. The translator who works with a literary text and has no opportunity to consult the author of the source text is a co-author of the target text to a certain extent, as during the work with the original text fragments, he/she is free to choose any means of indicating the reference meaning which seems optimal to him/her, provided that this means does not distort the sense of the initial speech situation. V.N. Komissarov points out the necessity of the correspondence of the translation activity product with the basic qualitative parameter - adequacy, defining an adequate translation as "a translation that provides the pragmatic tasks of the translation act at the maximum possible level of equivalence for achieving this goal, without violating the rules or usage of the translated text, respecting the genre and stylistic requirements to texts of this type and compliance with the conventional standard of translation" (Komissarov, 2013: 228). Achieving the adequacy of the translation may require the translator to use special means and techniques, for example, translation transformation, as a result of which the reference point may shift.

The translator, as a native speaker of the target language, can enforce the basic requirements for the translated text: equivalence, integrity, etc. "The equivalence rule ... means the need for the best possible identity of content in the source and target texts, but only to the extent where this identity is compatible with other regulatory requirements providing the adequacy of translation" (Komissarov, 2013: 229). The correct transfer of referential relations is one of the important features of adequate translation and a necessary condition for ensuring complete and correct understanding of the text by the listener. V.N. Komissarov asserts that "by definition, any adequate translation must be equivalent", i.e. reproduce "the content of the original text": the denotative and connotative content of the units that form the source text, and the "pragmatic potential" of the target text. To fulfill the requirement of equivalence, it is necessary not only to choose the linguistic unit that is suitable in a certain context, but also to designate the same referential relations as in the source text. This necessity is determined by the potential ability of the designated reference type to influence the reader's understanding of the text by regulating the correlation of a noun or a nominal group with a particular object of the extralinguistic reality.

The indication of the reference type of a noun, to which the article relates, is the main purpose of the article. The indication of the referential aspect of the meaning of a noun or a nominal group makes it possible to correlate a linguistic unit with the point of the extralinguistic space where the referenced object is located. An article may point to the reference of a noun with an object or a bounded real-world area, the virtual, fantasy or textual reality. In case of translation of the text of a literary work, a reference is established between an object of the textual reality (the image contained in the corresponding fragment of the original work) and a noun (nominal group) in the target text. A distinctive feature of such referential relations is their conditional subsidiarity: the initial reference is established between a noun (nominal group) of the text in the source language, and the reference of the noun contained in the target text is established relative to the original text fragment that contains not the original object, but its understanding and the author's perception of the original text. This is due to the fact that new participants appear in the translation as an act of communication, uncharacteristic for monolingual written or oral communication - a translator and a reader of the target language. Relatively speaking, the target text indicates the referent perceived and transmitted by the translator regarding the noun reflecting the author's interpretation of the original referential relations of this noun

XLinguae, Volume 12, Issue 2, April 2019, ISSN 1337-8384, eISSN 2453-711X 
and the original object of the extralinguistic reality. According to O.I. Moskalskaya, "the text describes the real situation from the point of view of the fictional world invented by the author" (Moskalskaya, 1981: 99). V.A. Marinchak develops this idea by saying that "the text is referenced to a certain continuum" and this continuum is comprehensive, although it may not be identical to the human realm (Marinchak, 1982: 161).

\section{Results}

The contrastive analysis conducted during the study allows drawing the following conclusions.

A category of reference in different languages is expressed through various means and can be either implicit or overt. In the articled languages, an indication of the reference type of nouns and nominal groups is ensured by the article system, the components of which can be expressed morphologically or represented as a zero sign.

One of the article invariants corresponds to each article form. The invariant of the definite article points to a subset selected from a common set of objects. An invariant of the indefinite article indicates an object of the set without any special features to distinguish it from the common set. An invariant of the zero article points to the correlation of a noun with a setting within which it is impossible to single out separate elements.

If there is a discrepancy in the interpretation of the original language situation recorded in the source text and conveyed by the translator using the means of the target language, a mismatch in the choice of articles by different translators may occur. These discrepancies are caused by the ambiguity of the indications of the reference type of a noun in the source text. The absence of unambiguous instructions can take different forms - as one indication that can be understood in different ways and as several simultaneously existing indications of the referential meaning of one noun. When implementing any ambiguous instructions in the source text, the translator makes an independent referential choice. Obviously, as a result of this choice, different translators may have different understandings of the reference type of a noun.

Since the source language is the articleless Russian language, in which the reference is an implicit category, the existence of several markers of the referential meaning for one noun in the original text does not contradict the language rule. In the Russian language, the referential meaning is conveyed by a large number of different means indicating the reference type as an additional and optional feature. These can be lexical means (pronouns, numerals, demonstrative particles, pronominal adverbs, adjectives, etc.) and grammatical, syntactical means (word order, theme and rhema).

When translating from the articleless language into the articled one, a translator expresses the original meaning of the implicit language category by means of the overt category. Languages which have such part of speech as the article reflect the perception of the world by its native speakers, who pay significant attention to the correlation of the units of speech with extralinguistic objects. At the same time, native speakers of articleless languages do not perceive the referential meaning of nouns and nominal groups as requiring unambiguous indicating the type of relations between a noun and an extralinguistic object.

The study showed that in the articleless languages, the burden of determining the reference type of a noun is often shifted from the speaker to the listener; thus, when translating into the articled languages, the different perception of meanings by different translators and, as a consequence, the choice of different articles, can occur. But all translators are obviously limited by the set of referential meanings that do not contradict the source text. 


\section{Discussion}

When studying the target texts and the reference of the nouns and nominal groups in them, the assumption was made that the author of the source text conveying the relation of the reference of nouns and analogues with an object of virtual (fantasy) reality unerringly establishes the nature of referential links, but for their nomination in the text he/she can use linguistic units that do not ensure an unambiguous interpretation of the reference type by the reader. The translator as an addressee of the original literary work perceives the reference indicated in the original text and, in the absence of a specific indication of the reference type, is compelled to make an independent referential choice based on his/her own, obviously subjective understanding of the original text fragment and its links with the context and the extra-textual reality.

In addition to the volitional component (implemented wish and/or intention of the translator to choose a certain article), in the process of selecting the article for the indication of referential relations embodied in the original text fragment, the article system of the target language also plays an important role (e.g. specificity of the area of meaning of article forms, the number of components of the system, the semantic distinction of these components and other factors).

In the most general case, the article (in any articled language) indicates the correspondence of the speech unit established by the subject of a communication to the object of extralinguistic reality. The speech image is formed under the influence of two main factors. The first factor is the objective conditions and circumstances that directly determine the nature of referential relations. They are outside the speaker's conscience and do not depend on him/her. These external factors are perceived and taken into account by the speaker when forming a part of the statement, which contains an indication of the reference type. The second factor is the speaker's subjective understanding of the organization of the external world. In accordance with this understanding, the speaker forms "a system of images reflecting this world" (Benveniste, 1974: 85), contained in his/her consciousness and subconsciousness, and directly influencing the interpretation of external circumstantial signals perceived by the speaker, associated with indicating the reference type and the subsequent implementation of the referential choice.

When translating from the articleless language into the articled one, there is a change in the properties of the reference category and ways of indicating the referential relations. The absence of a special linguistic category (part of speech) for indicating the reference of a noun together with the need for such indication causes the implicit indication of the nature of referential relations in the articleless languages. Thus, the category of reference in the Russian language refers to so-called implicit language categories. Yu.L. Sidorova writes about this: "The Russian category of certainty/uncertainty appears as an implicit lexico-semantic one if its indicators are pronominal words and analogs of the articles, short and full forms of adjectives, adverbs, predicates and verbal forms of the perfect and imperfect type" (Sidorova, 2006: 10), It can have an impact on the translator's perception of the referential relations indicated in the source text.

There is no sequential expression of deixis by means of articles in articleless languages. Nevertheless, it is evident that the absence of a separate part of speech specially used to satisfy the necessity of indicating the reference type (deixis is actually a special case) does not eliminate the need for such indication.

The features of the articleless language cause the appearance of additional (in comparison with the articled languages) questions about the essence of the reference and the referent. A researcher of the Russian grammatical system O.S. Akhmanova considers the following question relevant and controversial: "the question of what is to be understood by so-called elements of reality $<\ldots>$, how to define 'an object' or 'a

XLinguae, Volume 12, Issue 2, April 2019, ISSN 1337-8384, eISSN 2453-711X 
referent', i.e. what this expression refers to" (Akhmanova, 1957: 236). She points out the impossibility in case of the Russian language to be sure that "different ways of naming with different means" "refer to the same 'subject"' (Akhmanova, 1957: 236).

The nature of the reference of a noun in Russian can find the lexical expression at the pre-grammatical, discursive level in the form of quasi-articles - deictic pronouns and numerals with the stable referential meaning (Kasatkina, 2012: 4).

T.V. Bulygina and A.D. Shmelev define the reference as "distributive definiteness" or uncertainty of a noun in its connection with an extralinguistic object and note that "the difference between $<\ldots>$ the two meanings - specific and nonspecific references - should be recognized as grammatically essential for the Russian language" (Bulygina - Shmelev, 1997: 26). In addition to the specific and nonspecific reference in the Russian language system, T.V. Bulygina and A.D. Shmelev single out another type of referential relations, which they call "generalized reference" and define as "the neutral use", which does not have a specific subject referent in the general set of named objects. The authors separately indicate that "for nominalizations that denote the facts, the generalized reference is excluded as such nominalizations cannot be correlated with classes" (Bulygina, Shmelev, 1997: 116). In the opinion of these researchers, for naming specific objects and certain facts of reality in the Russian language, the so-called subject reference types (specific and non-specific) are used (Kashkin, 1999).

F. Cermak notes that in the languages lacking a special part of speech that "signals what function is performed by a noun", the meaning of certainty/uncertainty "is expressed more subtly" by means of "diverse ways" and, mainly, indefinite and demonstrative pronouns (Cermak, 2011).

Obviously, despite the absence of the category of article, in the circumstances of the need to indicate the reference type of nouns and nominal groups in the Russian language typical means of designating the referential component of nouns were formed. These include linguistic units that can directly point to the reference type, as well as grammatical, syntactic constructions and even communicative techniques and parameters of the utterance.

The opinion of V.B. Kashkin deserves particular attention as he considers the Russian language to have a "proto-article" in its composition. The researcher understands this term as a set of grammatical, lexical and suprasegmental means of expressing certainty, uncertainty and irrelevance of the indication of individualization or generalization of the named object (i.e. actually naming an integral set with the expression of the corresponding referential meaning). V.B. Kashkin points that in Russian, Bulgarian and a number of other languages there is a phenomenon of "grammatical prosody", which performs the functions of the article (Kashkin, 1999). Grammatical prosody is a combination of intonation, logical stress and word order in a phrase (for example, in a sentence). Most researchers recognize the word order as one of the main ways of expressing the reference type of a noun in the Russian language.

A. Pereltsvaig says quite the same emphasizing the universality of the word order in various nominal groups both in the articled and articleless languages. This researcher notes the presence of special characteristics of nominal groups containing prenominal possessives and concludes that such nominal groups have the referential meaning of individualization (Pereltsvaig, 2007: 79).

Within this scientific work, an attempt has been made not only to systematize the already available data on the ways of expressing such implicit category as the reference of a noun by means of the Russian language, but also to conduct the study that allows correlating units of the articleless language and unrelated articled languages with common semantic invariants.

For this comparison, an attempt to construct a maximally consistent theory has been made, so that it can describe the mechanism for choosing the article to convey 
the reference of a noun when translating from articleless Russian into English and French.

During the analysis, the sample, which included all nouns and nominal groups without determinants other than the article, was made. In total, 4,975 nouns and nominal groups forming 1,312 tetrads/triads that correspond to the stated criteria and are subject to the contrastive analysis were recorded, of which 1,039 complete tetrads and 273 triads (in one translation there is no material for comparison). Of these 909 matches and 378 mismatches were noted. The fixed mismatches are differentiated according to a number of criteria, such as the "reference frame" (intralinguistic and interlanguage mismatches), the nature of the mismatch (the features of the language structure, the possibility of an ambiguous interpretation of the reference in the source text fragment).

In total, three types of matches and mismatches were identified:

1) complete matches (all translators used the same article);

2) intralinguistic mismatches (three translators used the same article, the fourth translator used another article, or there were mismatches within each of the monolingual pairs of translations);

3) interlingual mismatches (intralinguistic matches of the articles do not coincide with each other).

A total of 295 interlingual mismatches and 197 intralinguistic ones are recorded, 89 of which are in English, and 109 - in French. A significant predominance of matches confirms the hypothesis that the functioning of the article is based on comparable principles in compared languages. The basis of these principles is the existence of a common semantic article invariant in the studied languages. The presence of mismatches in a statistically significant amount indicates that, in the absence of specific indications of the reference type in the source text, a translator who is both "a listener" and "a speaker", relying on his/her own understanding of the source context, makes an independent referential choice. Due to the obvious impossibility of direct observation of this process, it is possible to construct only a conditional model of the referential choice made when translating a written text.

In total, during the scientific work, three factors have been identified that affect the use of articles to indicate the reference type and have a basis in the source text, i.e. reflecting the features of transfer of the referential meaning in the original articleless language.

The first factor is different interpretations of one dual basis for using the article. Thus, in the context -

А велика ли сумма? //

and is it a large sum? //

And is it a large sum? //

La somme est-elle importante? //

La somme est-elle importante? (глава XXV)

the basis for using the article is the indication of the reference type of the noun sum in the original text fragment, but the referential component of the meaning of this noun can be interpreted in different ways, which was manifested in the use of different articles by the translators. Two translators considered the object sum as correlated with the part of the set without individualized features. As a result of this interpretation of the original referential meaning, the translation uses an indefinite article with the meaning of the invariant "reference to the class". The syntactic structure of the original context is also a reason for this choice; in this context the noun sum is in the rhematic position and introduced into the narration. Two translators perceived the same object sum as selected from the set and used the definite article with the invariant 'selection from the class' to indicate the reference type. The reason for this preference is the semantic structure of the source text fragment, where the noun sum is actually a contextual synonym for the previously mentioned noun money.

XLinguae, Volume 12, Issue 2, April 2019, ISSN 1337-8384, eISSN 2453-711X 
The second factor that determines the preference of a translator for an article to indicate the reference type of a noun is the choice of different, simultaneously present in the original text, indications by different translators. The presence of several directives that do not coincide in their meaning is mainly caused by the peculiarities of the indication of the referential relations in the original articleless language. For example, in the context

редактор толстого художественного журнала //

editor of a literary magazine //

the editor of a thick literary journal //

rédacteur en chef d'une épaisse revue littéraire //

rédacteur en chef d'une revue littéraire epaisse (глава I)

there was a mismatch in the use of articles in the translations, and three translators preferred an indication of the reference type "class naming", considering the object "editor" as representing a homogeneous class within which it is impossible to single out individual elements. In one translation into English, as the basis for determining the reference type, the reference to naming the selected part of the set is taken since in a broader context the fragment "editor of a thick art magazine" is an attachment to the nominal group "Mikhail Aleksandrovich Berlioz", which individualizes an object called by the noun "editor". This understanding of the indication of the reference type in the source text corresponds to an invariant of the article with the meaning "selection from the class".

The third factor, based on which the translator makes a referential choice, is the possibility of considering the language situation from different points of view and applying different principles of interpreting the original indication to the reference type. An example of the effect of this mismatch factor is provided in Chapter I:

к пестро раскрашенной будочке //

for the colorfully painted refreshment stand //

towards a colorfully painted booth //

vers une baraque peinturlurée //

vers un kiosque bariolé.

In this context, the intralinguistic mismatch is observed due to the specifics of indication of the reference type in the source text. In three translations, the language situation is viewed from the position of the listener, who does not know exactly what kind of booth is at issue, defining this object as belonging to a class and conveying this meaning by means of an indefinite article. In one translation into English, the context is viewed from the position of the narrator, i.e. the speaker, who has enough information about what object the noun booth is related to, and defines the reference type as "selection from the class", using a definite article with the corresponding meaning of the invariant.

\section{Conclusion}

The category of reference exists in all languages of the world and, depending on the language, can have either implicit or explicit expression. In the articled languages, the indication of the reference type of nouns and nominal groups is provided by means of a certain part of speech specially used for conveying the referential meaning of nouns. Components of the article system can be both morphologically expressed or have no morphological expression, being a zero sign. All the article forms included in the system of the article in a particular language correspond to one of the semantic invariants. The correspondence of the article forms to invariants makes it possible to conduct the interlingual analysis.

In an articleless language, the reference is an implicit category and the referential meaning is conveyed through a variety of lexical, grammatical and syntactic means for which the indication of the reference type of a noun is not the main function. This 
is due to the fact that speakers of articleless languages pay less attention to the referential meaning of a noun than the speakers of articled languages.

The language situation that allows more than one variant of the message's interpretation by the addressee manifest itself at the text level as mismatches in the use of the article, indicating the ambiguousness of the indication to the reference type of a noun, and at the level of cognitive processes it strengthens the influence of the linguistic personality on the perception of the source text and determines the subjective nature of the referential choice.

A particular feature of the translated fictional discourse is the impossibility to receive any feedback from the author of the source text when working on certain text fragments, which forces a translator to determine the referential points and the reference type of a noun independently, transferring the corresponding meanings using certain article forms. Examination of the results of translation practice and contrastive analysis of parallel texts allow analyzing the features of the expression of the reference type of a noun in Russian and studying the problem of translating certain implicit language categories.

The study does not cover the whole depth of the problem of studying the functioning of linguistic units, indicating the reference type of a noun in different languages. In the future, it is possible to carry out a comparative analysis of the functioning of articles in unrelated languages and make a further study of determinants that indicate the reference type of nouns and nominal groups.

\section{Bibliographic references}

AKHMANOVA, O.A. 1957. Essays on General and Russian Lexicology. Moscow: Utchpedgiz.

ARNOLD, I.V. 1982. Implication as a Method of Text Constructing and the Subject of Philological Study. In: Voprosy yazykoznaniya, issue 4, pp. 83-91. ISSN 0373-658X

BARDA, I.S. - MITCHELL, P.J. 2016, Common Mistakes in the Use of Articles When Translating Research Papers into English. In: Yazyk i kultura, issue 36, pp. 612. ISSN 2410-9266

BARKHUDAROV, L. 1975. Language and Translation: Issues of General and Specific Theory of Translation. Moscow: Mezhdunarodnye otnosheniya.

BARTON, D. - KOLB, N. - KUPISCH, T. 2015. Definite Article Use with Generic Reference in German: An Empirical Study. In: Zeitschrift für Sprachwissenschaft, vol. 34, issue. 2. ISSN 1613-3706

BENVENISTE, E. 1974. General Linguistics. Moscow: Progress.

BOULGAKOV, M. 2004. Le Maitre et Marguerite (F. Flamant, Trans.). Paris: Editions Gallimard. ISBN 9782070439553

BOULGAKOV, M. 2012. Le Maitre et Marguerite (C. Ligny, Trans.). Pars: Robert Laffont. ISBN 978-2266134378

BULGAKOV, M. 1997. The Master and Margarita (D. Burgin, and K.T. O'Connor, Trans.). London: Picador. ISBN 0330351338

BULGAKOV, M.A. 2001. Master i Margarita. Moscow: AST. ISBN 978-5-17066102-2

BULGAKOV, M.A. 2008. The Master and Margarita (H. Aplin, Trans.). London: One World Classics. ISBN 978-1847492425

BULYGINA, T.V. - SHMELEV, A.D. 1997. Language Conceptualization of the World (on the Basis of Russian Grammar). Moscow: Shkola 'Yazyki Russkoi Kultury'. ISBN 5-88766-051-1

CERMAK, F. 2011. Jazyk a jazykoveda. Praha: Univerzita Karlova v Praze. ISBN 80246-0154-0. 
CONTEMORI, C. - DUSSIAS, P.E. 2016. Referential Choice in a Second Language:

Evidence for a Listener-Oriented Approach. In: Language Cognition and Neuroscience, issue 31/10, pp. 1257-1272. ISSN 1464-0732

DOLININ, K.A. 1983. Implicit Statement Content. In: Voprosy yazykoznaniya, issue 6, pp. 37-47. ISSN 0373-658X

KASATKINA, R.F. 2012. The Russian Language Is Looking for the Article. In: Voprosy yazykoznaniya, issue 2, pp. 3-9. ISSN 0373-658X

KASHKIN, V.B. 1999. An Indefinite Article in the Beginning of a Fairy Tale. In: Vocabulary and Lexicography, issue 9, pp. 95-102. ISSN 1605-7880

KOMISSAROV, V.N. 2013. Theory of Translation (Linguistic Aspects). Moscow: Alyans. ISBN 978-5-91872-024-0

KUBRYAKOVA, E.S. 1997. Space of Language and Language of Space. In: Izvestiya AN. Seriya literatury i yazyka, vol. 56, issue 3, pp. 22-31. ISSN 1605-7880

LITVIN, F.A. 2014. General and Nationally Specific in the Semantics of the Article in Different Languages. In: Obshchestvo i chelovek, n. 2(8), pp. 89-99. ISSN 2218-9728

MARINCHAK, V.A. 1982. Analysis of the Semantic and Syntactic Organization of the Text (on the Basis of Russian Scientific Speech): Thesis for the Degree of Candidate of Philology. Kharkov.

MOSKALSKAYA, O.I. 1981. Text Grammar. Moscow: Vysshaya shkola.

PERELTSVAIG, A. 2007. The Universality of DP: A View from Russian. In: Studia Linguistica, n. 61(1), pp. 59-94. ISBN 978-5-906

SIDOROVA, Yu.L. 2006. Lexical Means of Implementing the Category of Certainty/Uncertainty in the Russian Language: Author's Abstract of the Dissertation for a Scientific Degree of Cand. Phil. Sci. Novosibirsk.

TIMOSHENKO, I.V. 2017. To the Matter of Functioning of Articles in Nominal Groups in English and French (on the Material of Translations from Russian). In: Vestnik Voronezhskogo gosudarstvennogo universiteta, issue 3, pp. 117-120. ISSN $1680-5755$

Words: 6462

Characters: 41811 (23,23 standard pages)

Irina V. Timoshenko

Department of English Philology

Institute of Foreign Languages,

Orel State University,

95 Komsomolskaya Str.,

302026, Orel

Russian

tlmoshenko@outlook.com 